\title{
The association of physical fitness with mental health in children: A serial multiple mediation model
}

\author{
Yansong $\mathrm{Li}^{1} \cdot$ Xue Xia ${ }^{2} \cdot$ Fanying Meng ${ }^{3} \cdot$ Chunhua Zhang ${ }^{1}$ \\ Accepted: 22 December 2020 / Published online: 3 January 2021 \\ (C) The Author(s), under exclusive licence to Springer Science+Business Media, LLC part of Springer Nature 2021
}

\begin{abstract}
There is growing interest in the association between physical fitness and mental health. This study aimed to extend current knowledge by investigating the potential mediating roles of resilience and anxiety in the association between physical fitness and mental health in children. A total of 269 children were selected by stratified random sampling from three primary schools in China. Physical fitness was scored using the Chinese National Student Physical Fitness Standard. Resilience, anxiety, and mental health data were collected using the following questionnaires: Resilience Scale for Chinese Adolescents, Multidimensional Anxiety Scale for Children, and the Mental Health Test. The PROCESS macro developed by Hayes was used to conduct serial multiple mediation analysis. We found that physical fitness, resilience, anxiety, and mental health were significantly correlated. Children with higher physical fitness had lower mental health problems; however, this statistical significance was not detectable after controlling for resilience and anxiety. Serial multiple mediation analysis revealed that the association of physical fitness with mental health was partially mediated by resilience and anxiety. These results indicate that the positive association of physical fitness with mental health in children may be changed through resilience and anxiety, which appear to play serial multiple mediating roles in this association. These findings contribute to deeper understanding of the associations between these factors and suggest that promoting physical fitness independent of considering resilience and anxiety may be insufficient to achieve good mental health in children.
\end{abstract}

Keywords Physical fitness $\cdot$ Resilience $\cdot$ Anxiety $\cdot$ Mental health $\cdot$ Children

\section{Introduction}

The rate of mental health problems (MHPs) diagnosed among children has been increasing, and MHPs in children are becoming a global issue (Beecham, 2014; Kieling et al., 2011). For example, in the United States, the percentage of children with MHPs in any one year was 13\%-20\% from 1994 to 2011, with the prevalence increasing during that time (Perou et al., 2013). Similarly, MHPs are estimated to affect at least $20 \%$ of the children in the region of South Asia (Maselko et al., 2016). The best estimates from studies conducted in Europe have suggested a prevalence of MHPs of almost

Chunhua Zhang zch20080808@126.com

1 School of Kinesiology, Shanghai University of Sport, Shanghai, China

2 School of Psychology, Shanghai University of Sport, Shanghai, China

3 Institute of Physical Education, Huzhou University, Huzhou, China
$35 \%$ (Rodriguez-Ayllon et al., 2018), and the percentage of children reported with an MHP is approximately $14 \%$ in both Canada and Australia (Lawrence et al., 2016; Waddell, McEwan, Shepherd, Offord, \& Hua, 2005). MHPs are critical factors that adversely affect the development of children. Children who experience MHPs have poorer academic achievement (Guzman et al., 2011) and decreased ability to maintain stable relationships (Gallagher \& Mechanic, 1996). MHPs also cause functional impairments (Costello, Mustillo, Erkanli, Keeler, \& Angold, 2003) and increase the risk of suicide among children (Chronis-Tuscano et al., 2010). Furthermore, $50 \%-75 \%$ of adult MHPs begin in childhood or adolescence (Kessler et al., 2012) and can lead to negative outcomes. Hence, strategies to improve psychological wellbeing and decrease MHPs in children are needed.

Previous research has shown that numerous factors affect the prevalence of MHPs in children, including socioeconomic status (Reiss, 2013), maternal influences (Hardie \& Landale, 2013), school experiences (Schulte-Korne, 2016), physical activity (Parfitt, Pavey, \& Rowlands, 2009), special healthcare needs of the child, family function, and the living environment 
(Goldfeld \& Hayes, 2012). Among these factors, physical activity is often suggested as a low-cost strategy for improving children's mental health (Biddle, Ciaccioni, Thomas, \& Vergeer, 2019). Physical fitness is the body's ability to perform physical activity (Rodriguez-Ayllon et al., 2018), and physical fitness is more predictive of health outcomes in children than is physical activity (Bovet, Auguste, \& Burdette, 2007). Although physical fitness is considered one of the most important health markers, literature focused on the association between physical fitness and mental health is scarce (Ortega, Ruiz, Castillo, \& Sjostrom, 2008). Recently, there has been growing interest in this association (Aparicio et al., 2019; Avitsland et al., 2020), but few studies have provided objective data to evaluate comprehensive physical fitness and its direct or indirect effects on children's mental health. Physical fitness in children typically has been evaluated using only specific components, whereas the concept of physical fitness should encompass many dimensions and types of testing (Dong et al., 2020). Given these limitations of the current literature, studying physical fitness as defined using a comprehensive set of components is needed to understand the mechanisms underlying the association of physical fitness with mental health in children.

The coronavirus disease 2019 (COVID-19) pandemic has threatened both physical and mental health (Holmes et al., 2020; PeConga et al., 2020). This unprecedented crisis has also provided the opportunity for researchers to gain insight into the potential associations between various factors (Barzilay et al., 2020). For example, a study by PeConga et al. (2020) suggested that long-term resilience will be the most common outcome impacted by the pandemic (PeConga et al., 2020). According to the American Psychological Association, resilience is defined as the process of adapting well in the face of adversity, trauma, tragedy, threats, or even significant sources of stress (Chamratrithirong, Lucktong, Jampaklay, \& Ford, 2020). Resilience is being explored increasingly in mental health research because it may help explain individual, group, and community protective mechanisms (Poudel-Tandukar et al., 2019). Tang, Xiang, Cheung, and Xiang (2020) have shown that during the COVID-19 pandemic, resilience and MHPs coexist in children. This finding suggests that resilience is not solely a quality within individuals; instead, resilience grows from access to and the use of resources needed to support mental health. As a protective factor, resilience is expected to be a crucial maintenance element for physical and mental health. Another study has shown that during the COVID-19-related school closures in Shanghai, China, the most prevalent MHP in children and adolescents was anxiety (Tang et al., 2020). Anxiety symptoms in childhood can have long-term detrimental influences on physical and mental health even without meeting diagnostic criteria for a given anxiety disorder (Ma, Serbin, \& Stack, 2019). Bittner et al. (2007) found anxiety in children to be a predictor of a range of MHPs in adolescence (Bittner et al., 2007). Given that anxiety in youth has a chronic course for some individuals and also predicts later development of other MHPs, it is important to identify factors early in development that may predict anxiety symptoms (Kertz, Sylvester, Tillman, \& Luby, 2019). Protective and key risk factors warrant further study to understand potential associations in the maintenance of good mental health in children. Resilience and anxiety have been widely studied in the context of sports as they relate to success and performance (Zurita-Ortega, Chacon-Cuberos, Cofre-Bolados, Knox, \& Muros, 2018). However, research investigating the associations between physical fitness and resilience or anxiety is limited (Kandola et al., 2018; Lavoie, Pereira, \& Talwar, 2016), and even these limited studies often discuss the association based on a specific component of physical fitness rather than based on a comprehensive physical fitness evaluation (PozueloCarrascosa et al., 2017; Williams, Carroll, Veldhuijzen van Zanten, \& Ginty, 2016).

In addition, from a stress perspective, physical fitness seems to help an individual buffer the potentially harmful impact of stress on mental health (Wyss et al., 2016). It can also confer resilience owing to its stress-buffering effects (Silverman \& Deuster, 2014). Moreover, resilience acts as a stable, protective factor that facilitates positive adaptation to stress and enables the individual to avoid stress-related MHPs, such as depression, posttraumatic stress disorder, and anxiety (Liu, Zhang, Ji, \& Yang, 2018; Petrowski, Brahler, \& Zenger, 2014). On the other hand, a recent narrative review finds that physical fitness is beneficial to mental health and may help promote resilience in youths affected by MHPs (Belcher et al., 2020). Given these roles, we hypothesized the existence of a serial mediating path from physical fitness to mental health via resilience and anxiety.

To test this hypothesis, the current study used a serial mediation model to probe the association between physical fitness and mental health in children. This is a novel way to approach testing the multiple variables of the association. Whereas parallel mediation models assume that no mediator causally influences another, no such assumption is made in serial mediation, enabling the testing of a specific theoretical sequence among the variables. Thus, the advantage of this statistical method is that multiple pathways between the variables can be tested and we can ascertain which are significant using one model (Carnahan, Carter, \& Herr, 2020). Furthermore, we can determine whether the order of the variables plays a significant role to provide additional supporting evidence for the theoretical model. To our knowledge, no study has explored the joint role of resilience and anxiety as mediators of the association between physical fitness and mental health. Thus, the aims of the present study were twofold: (1) to analyze the associations among physical fitness, resilience, anxiety, and mental health in children; and (2) to determine whether any detected association of physical fitness with mental health was mediated by resilience or anxiety. 


\section{Methods}

\section{Participants and Procedure}

The current study selected participants based on relevant research and using stratified random sampling from three primary schools in Shanghai (China); schools were selected for their representativeness, accessibility to our research team, and availability of the teachers to assist with logistics. Potential participants who did not have any disease that made it impossible to complete the test, and understood each item in the questionnaires were included. After the study's aim was explained, participants completed the objective measurements and self-reported questionnaires under the supervision of trained volunteers. For children in the lower grades, each question in the questionnaires was explained in a uniform manner by trained volunteers. If a question confused a child, the child was allowed to immediately ask the trained volunteers for additional clarification. However, other than clarifying the questions for children, the volunteers were instructed to avoid providing any help in answering the questions. Participants whose physical fitness test results exceeded the logical limits, or whose questionnaires were considered invalid were excluded. Valid variables were obtained from 269 participants. The participants were in school grades 2 through 5 and comprised 126 boys and 143 girls, with ages ranging from 7 to 12 years (mean age $=9.75$ years; $\mathrm{SD}=1.17$ years). The number (percentage) of participants by school grade was $72(26.8 \%)$ in second grade, $67(24.9 \%)$ in third grade, 66 $(24.5 \%)$ in fourth grade, and $64(23.8 \%)$ in fifth grade. The flowchart for the study is shown in Fig. 1.

The study was conducted in accordance with the recommendations of the World Medical Association's Declaration

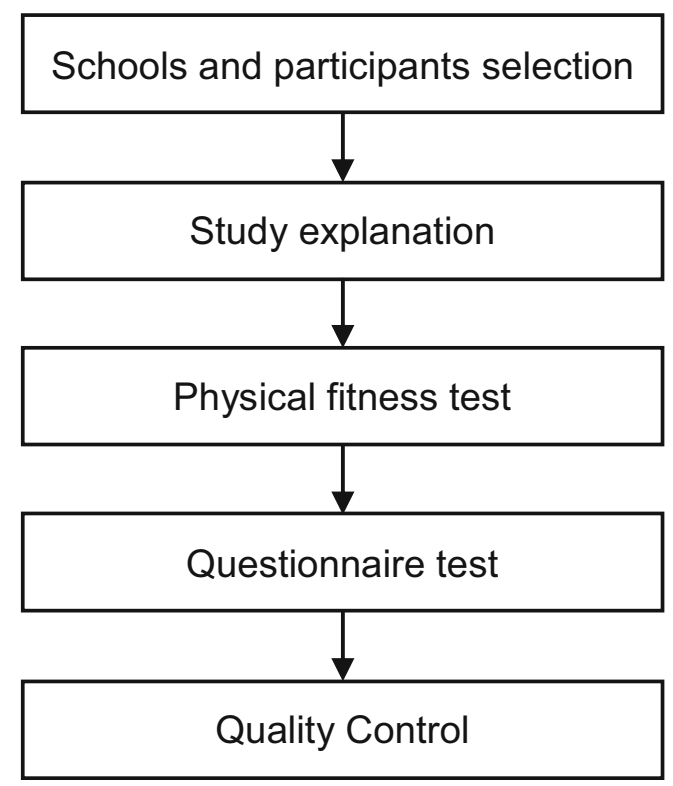

Fig. 1 Flowchart of the study working process of Helsinki and approved by the Shanghai University of Sport Ethics Committee. Written informed consent was obtained from the guardians of all participants.

\section{Measures}

Physical fitness was measured using the Chinese National Student Physical Fitness Standard (CNSPFS) (Zhu, Yang, Kong, Zhang, \& Zhuang, 2017). The CNSPFS is a reliable and valid instrument to assess physical fitness in children and is a norm testing battery used in China (Yi, Fu, Burns, Bai, \& Zhang, 2019). The physical fitness tests were conducted by trained volunteers from the Shanghai Research Center for Physical Fitness and Health of Children and Adolescents, who all majored in kinesiology and were familiar with the testing methods, to minimize variability. As indicated in the CNSPFS guidelines, the results of all fitness components were scored according to sex and school grade level. The total physical fitness score was composed of the product sum of the scores and weights of each component. The weights of the CNSPFS scores for each fitness component stratified by school grade are given in Table 1.

Resilience was defined using the Resilience Scale for Chinese Adolescents (RSCA) (Hu \& Gan, 2008). The RSCA had shown excellent psychometric properties and has been widely used in evaluating the resilience of Chinese children. It includes 27 items, classified into five factors: target concentration, emotional control, positive thinking, family support, and interpersonal assistance. Participants were asked to rate themselves on questions using a 5-point Likert scale ranging from 1 (not true at all) to 5 (true nearly all the time). The total score for the RSCA ranged from 27 to 135, with a higher score indicating a higher level of resilience. Cronbach's alpha in our sample was 0.74 .

Anxiety was obtained using the Chinese version of the Multidimensional Anxiety Scale for Children, a 39-item self-report scale for assessing anxiety during the previous week (March, Parker, Sullivan, Stallings, \& Conners, 1997). The items clustered into the following four scales: physical symptoms, harm avoidance, social anxiety, and separation anxiety. Response options ranged from 0 (never true) to 3 (often true). The total score (range, 0 to 117) was generated by adding the scores of all items; thus, a higher score reflected a greater degree of anxiety. Cronbach's alpha in the present study was 0.89 .

Mental health was assessed using the Mental Health Test, a popular method of evaluation that has shown high reliability and validity among Chinese children (Zhao \& Yu, 2016). There were 100 items within eight content subscaleslearning anxiety, interpersonal anxiety, loneliness, and physical symptoms as well as a tendency to self-blame, be oversensitive, panic, or be impulsive - and one validity subscale. Participants who answered "no" received 0, whereas those 
Table 1 Fitness components and weights of CNSPFS scores in school-age children $(\%)$

\begin{tabular}{|c|c|c|c|c|c|}
\hline \multicolumn{2}{|l|}{ Second grade } & \multicolumn{2}{|l|}{ Third and fourth grades } & \multicolumn{2}{|l|}{ Fifth grade } \\
\hline Fitness component & $\%$ & Fitness component & $\%$ & Fitness component & $\%$ \\
\hline BMI & 15 & BMI & 15 & BMI & 15 \\
\hline Vital capacity of lung & 15 & Vital capacity of lung & 15 & Vital capacity of lung & 15 \\
\hline $50 \mathrm{~m}$ sprint & 20 & $50 \mathrm{~m}$ sprint & 20 & $50 \mathrm{~m}$ sprint & 20 \\
\hline Sit and reach & 30 & Sit and reach & 20 & Sit and reach & 10 \\
\hline \multirow[t]{3}{*}{ Timed rope-skipping } & 20 & Timed rope-skipping & 20 & Timed rope-skipping & 10 \\
\hline & & Timed sit-ups & 10 & Timed sit-ups & 20 \\
\hline & & & & $50 \mathrm{~m} \times 8$ shuttle run & 10 \\
\hline
\end{tabular}

BMI body mass index; CNSPFS Chinese National Student Physical Fitness Standard who answered "yes" received 1 . In the validity subscale, participants with responses scoring more than 7 were removed from further analysis because a high score in the validity subscale is an indicator of participants answering questions as they deemed more socially desirable rather than as truthful. The total score was calculated by adding the scores in the eight subscales (range, 0 to 90 ), with a higher total score indicating greater MHPs. The Cronbach's alpha for this assessment in the present study was 0.90 .

\section{Statistical Analysis}

Both graphical (normal probability plots) and statistical (Kolmogorov-Smirnov test) methods were used to examine the fit to a normal distribution for each continuous variable, and all were found to fit a normal distribution. Harman's single-factor test was used to determine that there was no common method bias among the three questionnaire tests. Age and sex were selected as covariates, as both were associated with the key variables. Descriptive characteristics of the participants were presented as means \pm standard deviation (SDs) or as percentages.

Partial correlation coefficients were estimated to examine the associations among physical fitness, resilience, anxiety, and mental health while controlling for age and sex.

Analysis of covariance models were used to assess differences in the mental health scores across the physical fitness, resilience, and anxiety categories, while controlling for age and sex (model 1), and then adjusting physical fitness, resilience or anxiety as covariates depending on the fixed factor (model 2). Pairwise post hoc hypotheses were tested using the Bonferroni correction for multiple comparisons.

Physical fitness, resilience, and anxiety were categorized by quartiles $(\mathrm{Qs})$, with the first quartile $(\mathrm{Q} 1)$ being the lowest, followed by second and third quartiles (Q2/3), and the highest being the fourth quartile (Q4), as described and used in previous studies (Garcia-Hermoso, Esteban-Cornejo, Olloquequi, \& Ramirez-Velez, 2017; Pozuelo-Carrascosa et al., 2017).
Serial multiple mediation analysis was conducted to examine whether the association of physical fitness with mental health in children was mediated by resilience or anxiety using Hayes' PROCESS macro for SPSS (Hayes, 2018). The goal of this model was to investigate the total (c) and direct effects $\left(a_{1}, a_{2}, b_{1}, b_{2}, d_{21}\right.$, and c'), reflected by the standardized regression coefficient and significance among the independent and dependent variables, and to assess 3 indirect effects $\left(\mathrm{IE}_{1}\right.$ : $a_{1} * b_{1} ; I E_{2}: a_{2} * b_{2} ; I E_{3}: a_{1} * d_{21} * b_{2}$ ) that showed a change in mental health status for every 1 unit change in physical fitness that was mediated by the potential mediator (resilience or anxiety or both). Age and sex were adjusted in this model.

Mediation hypotheses were tested using the bootstrapping method, with a resample procedure of 10,000 samples to calculate $95 \%$ confidence intervals (CIs) (Preacher \& Hayes, 2008). IEs were deemed significant when the CI did not contain zero.

Statistical analyses were performed using SPSS version 22.0, and the level of statistical significance was established as $p<.05$.

\section{Results}

Partial correlations among physical fitness, resilience, anxiety, and mental health while controlling for age and sex are presented in Table 2 . All correlation coefficients were statistically significant. A positive correlation was found between physical fitness and resilience $(r=.246, p<.001)$ and between anxiety and mental health $(r=.658, p<.001)$. Both physical fitness and resilience were negatively correlated with anxiety $(r=$ $-.253, p<.001 ; r=-.241, p<.001$, respectively) and with mental health $(r=-.318, p<.001 ; r=-.337, p<.001$, respectively).

Mean (SD) differences in mental health by physical fitness, resilience, and anxiety categories including different covariates (age, sex, physical fitness, resilience, or anxiety) are provided in Table 3 . In model 1, mean (SD) mental health scores were significantly lower in children with higher levels of physical fitness $(\mathrm{Q} 1,36.82 \pm 13.21$; Q2/3, $32.81 \pm 13.04$; 
Table 2 Descriptive statistics and correlation analysis results of each variable

\begin{tabular}{llccc}
\hline Variable & Test score $($ mean $\pm \mathrm{SD})$ & 1 & 2 & 3 \\
\hline 1. Physical fitness & $81.50 \pm 9.80$ & - & & \\
2. Resilience & $93.10 \pm 13.77$ & $.246^{* * *}$ & - & \\
3. Anxiety & $43.33 \pm 19.18$ & $-.253^{* * * *}$ & $-.241^{* * * *}$ & - \\
4. Mental health & $32.53 \pm 13.03$ & $-.318^{* * *}$ & $-.337^{* * * *}$ & $.658^{* * *}$ \\
\hline
\end{tabular}

and Q4, 27.67 \pm 11.27$)$ and resilience $(\mathrm{Q} 1,36.51 \pm 13.96$; $\mathrm{Q} 2 /$ 3, $34.05 \pm 12.67$; and Q4, $25.03 \pm 9.45$ ). By contrast, mental health scores were significantly higher in children with lower levels of anxiety (Q1, $44.68 \pm 10.52 ; \mathrm{Q} 2 / 3,31.90 \pm 10.24$; 4 , $22.58 \pm 10.62)$.

However, in model 2, after adjusting for resilience and anxiety, the statistical significance observed for the association of physical fitness with mental health was no longer detected ( $p=.076$ for the physical fitness category). Regarding resilience and anxiety categories, when physical fitness and anxiety or resilience were added as covariates, the $p$ value remained significant in both models as well as in the pairwise mean comparisons $(p<.001)$.

The serial multiple mediation analysis model is illustrated in Fig. 2. Physical fitness was positively associated with resilience $\left(\mathrm{a}_{1}=.249, p<.001\right)$ but negatively associated with anxiety $\left(\mathrm{a}_{2}=-.208, p<.001\right)$. Resilience was negatively associated with anxiety $\left(\mathrm{d}_{21}=-.190, p<.01\right)$ and mental health $\left(b_{1}=-.161, p<.001\right)$. Anxiety was positively associated with mental health $\left(\mathrm{b}_{2}=.574, p<.001\right)$. The association of physical fitness with mental health $(\mathrm{c}=-.315, p<.001)$ was partially mediated by resilience and anxiety $\left(\mathrm{c}-\mathrm{c}^{\prime}=\right.$ $-.187, p<.01$ ).

Mediation hypotheses testing was conducted with bootstrapping, and then the serial multiple mediation effect of the association of children's physical fitness level with mental health status was determined (Table 4). The percentage of total IEs mediated by resilience and anxiety was $59.4 \%$. The total IEs included 3 significant pathways: (1) $\mathrm{IE}_{1}$ : physical fitness - resilience - mental health $\left(\mathrm{a}_{1} * \mathrm{~b}_{1}=\right.$ $-.040,95 \% \mathrm{CI},-.071$ to -.015$)$; (2) $\mathrm{IE}_{2}$ : physical fitness anxiety - mental health $\left(\mathrm{a}_{2} * \mathrm{~b}_{2}=-.120,95 \% \mathrm{CI},-.208\right.$ to -.035); (3) $\mathrm{IE}_{3}$ : physical fitness - resilience - anxiety - mental health $\left(\mathrm{a}_{1} * \mathrm{~d}_{21} * \mathrm{~b}_{2}=-.027,95 \% \mathrm{CI},-.051\right.$ to -.007$) . \mathrm{IE}_{1}$, $\mathrm{IE}_{2}$, and $\mathrm{IE}_{3}$ accounted for $12.7 \%, 38.1 \%$, and $8.6 \%$ of the total effect, respectively.

\section{Discussion}

The present study is, to our knowledge, the first to analyze a four-way association - physical fitness, resilience, anxiety,
Table 3 Mean differences in mental health by physical fitness, resilience, and anxiety categories

\begin{tabular}{lllllll}
\hline $\begin{array}{l}\text { Physical fitness } \\
\text { Q1 }\end{array}$ & Q2/3 & Q4 & Model 1 & \multicolumn{3}{c}{ Model 2 } \\
$n=67$ & $n=135$ & $\mathrm{n}=67$ & $p$ & Bonferroni* $^{*}$ & $p$ & Bonferroni* $^{*}$ \\
$69.12 \pm 9.92$ & $82.58 \pm 3.14$ & $91.71 \pm 2.77$ & $<.001$ & Q1 $>$ Q4, & .073 & - \\
& & & & Q2/3 $>$ Q4 & &
\end{tabular}

\section{Resilience}

Q1

$n=68$

$\mathrm{Q} 2 / 3$

$76.75 \pm 8.34$

$n=137$

Q4

$n=64$

$92.72 \pm 5.21$

$111.28 \pm 7.06$

Model 1

p Bonferroni*

$<.001$

Q1 > Q4,

$\mathrm{Q} 2 / 3>\mathrm{Q} 4$

Model 2

$p \quad$ Bonferroni* ${ }^{*}$

$<.001 \quad \mathrm{Q} 1>\mathrm{Q} 4$,

Q2/3 > Q4

Anxiety

Q1

$n=65$

$\mathrm{Q} 2 / 3$

$69.29 \pm 12.02$

$n=133$

Q4

$n=71$

Model 1

$p$
$<.001$

$\begin{array}{ll}\text { Bonferroni* }^{*} & \text { Model 2 } \\ \text { Q1 }>\text { Q2 } / 3>\text { Q4 } & <.001\end{array}$

Bonferroni

$42.33 \pm 7.19 \quad 21.45 \pm 8.11$

Q1 > Q2/3 > Q4
Q1 > Q2/3> Q4

Variables are represented as mean $\pm \mathrm{SD}$. Categories are depicted as quartiles (Qs), with $\mathrm{Q} 1$ being the lowest, followed by Q2/3, and Q4 being highest. Higher mental health scores indicate greater mental health problems. Model 1: adjusted for age and sex; Model 2: model 1 covariates plus physical fitness, resilience or anxiety, depending on the fixed factor. *Pairwise post hoc hypothesis assessed with Bonferroni correction for multiple comparisons, $p<.05$ 
Fig. 2 Serial multiple mediation model showing the association between physical fitness and mental health with resilience and anxiety as mediators, adjusting for age and sex. Standardized regression coefficients are presented. $* * p<.01, * * * p<.001$

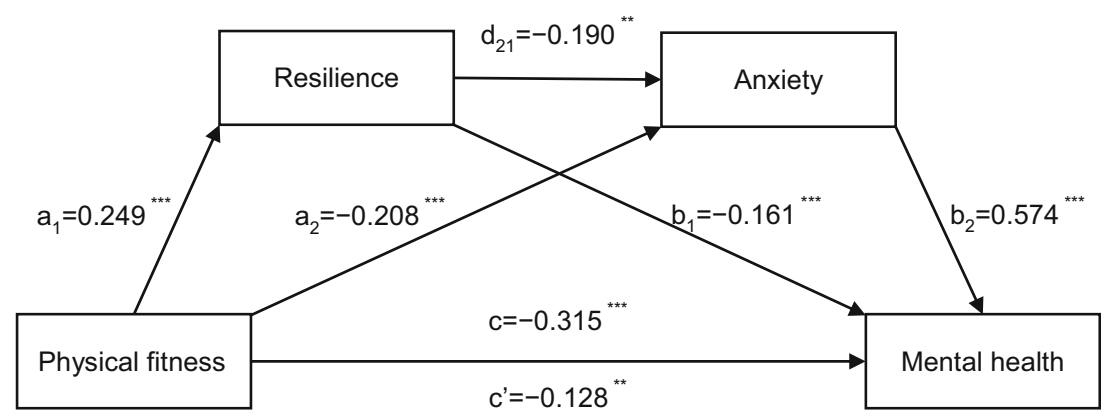

and mental health - in children by using serial multiple mediation analysis. The two main findings of our study were (1) that children with higher physical fitness levels were associated with lower MHPs although this association was not detected after controlling for resilience and anxiety, and (2) that resilience and anxiety mediated the association of physical fitness level with mental health status. These findings contribute to the current knowledge by providing evidence to support that physical fitness plays a crucial role in children's mental health and suggesting that physical fitness promotion appears to be related to improved resilience, decreased anxiety, or both, which could affect children's mental health.

In line with previous studies, our data showed that there was a close association of physical fitness with mental health in children. In addition, our results indicated that there was a direct effect, accounting for $40.6 \%$ of the association. Physical fitness is a critical part of the overall physical and mental health of children (Donnelly et al., 2016). Recent studies have investigated the relationship between some physical fitness components and mental health; for example, higher levels of muscular strength or cardiorespiratory fitness have been associated with better mental health (Pozuelo-Carrascosa et al., 2017; Rodriguez-Ayllon et al., 2018). There are also multiple behavioral and neurocognitive mechanisms that link aerobic fitness and mental health in youth (Belcher et al., 2020). The comprehensive physical fitness tests used in our study is the unified standard test commonly used in Chinese schools. Furthermore, it changed some fitness components (such as adding endurance tests) and score weights (such as decreasing the weight of the flexibility tests) to adjust for the growth and development of children. Thus, in the process of improving the level of mental health through physical fitness, combining physical activities or exercise interventions with such changes may lead to better effects on both physical fitness and mental health.

Our results also showed that the indirect mediating effect of resilience and anxiety on the association of children's physical fitness with their mental health accounted for $59.4 \%$ of the total effect. Among the 3 significant pathways, resilience $\left(\mathrm{IE}_{1}\right)$ and anxiety $\left(\mathrm{IE}_{2}\right)$ played indirect roles as independent mediating variables. $\mathrm{IE}_{1}$ examined resilience as a mediator in the association of physical fitness with mental health in children. A recent review found that physical fitness is beneficial to mental health and may help promote resilience in youths affected by MHPs (Belcher et al., 2020). The beneficial effects of physical fitness on resilience are based on solid scientific evidence; for example, from the perspective of biological mechanisms, physical fitness may promote resilience by optimizing neuroendocrine stress responses or minimizing inflammation (Silverman \& Deuster, 2014). On the other hand, resilience may be activated during stress to prevent the development of negative mental health outcomes (Morote, Hjemdal, Martinez Uribe, \& Corveleyn, 2017). Thus, when promoting physical fitness in children, improving their resilience may be an important factor affecting their mental health. $\mathrm{IE}_{2}$, the mediating effect of anxiety, accounted for $38.1 \%$ of the total effect, which was the major total IE, and thus may, to some extent, underlie the degree of the association of physical fitness with mental health. Previous studies have examined the association of physical fitness with anxiety; however, their findings are
Table 4 Indirect effects of physical fitness on mental health in children

\begin{tabular}{lcccc}
\hline Indirect Effect & Effect & Bootstrap SE & $95 \% \mathrm{CI}$ & Percentage accounting for total effect \\
\hline Total IEs & -.187 & .049 & -.284 to -.094 & 59.4 \\
$\mathrm{IE}_{1}$ & -.040 & .014 & -.071 to -.015 & 12.7 \\
$\mathrm{IE}_{2}$ & -.120 & .044 & -.208 to -.035 & 38.1 \\
$\mathrm{IE}_{3}$ & -.027 & .011 & -.051 to -.007 & 8.6 \\
\hline
\end{tabular}

Effect Standardized regression coefficients, SE Standard error, CI Confidence interval; IE indirect effect; IE $_{1}$ physical fitness - resilience - mental health; $\mathrm{IE}_{2}$ physical fitness - anxiety - mental health; $\mathrm{IE}_{3}$ physical fitness resilience - anxiety - mental health. The IE is statistically significant at the $95 \%$ CI when the CI does not include 0 
inconsistent. Few studies have shown that improvements in physical fitness are associated with reductions in levels of anxiety (Așç1, 2003; Cordoba-Torrecilla et al., 2016). But some scholars argue that no relationship exists between physical fitness components and anxiety indicators (Rodriguez-Ayllon et al., 2018). Our results support such an association. The discrepancies among the studies may be attributable to participants' demographic characteristics. Anxiety is prevalent in children and a precursor to negative mental health outcomes in adolescence and adulthood (Ma, Serbin, \& Stack, 2018). Effective interventions provided in the early stages, such as the first or early episodes of threshold anxiety, have the potential to rapidly improve mental health and prevent negative impacts on health outcomes (Hetrick et al., 2008). Our findings are consistent with the importance of anxiety on mental health in children and indicate that anxiety plays a crucial role in the association of physical fitness with mental health in children.

In our study, the association of higher-level physical fitness with good mental health was no longer present when resilience and anxiety were controlled for in a statistical model, which suggested that physical fitness directly affected resilience and anxiety, and then affected mental health. This meant that resilience and anxiety served as mediators of the association of physical fitness with mental health in children. Furthermore, our serial multiple mediation model revealed a more detailed picture of the mechanisms that associate physical fitness with mental health and provided a basis for improving children's mental health with physical fitness via resilience and anxiety. The $\mathrm{IE}_{3}$ pathway showed that the association of physical fitness with mental health was partially mediated by resilience and anxiety, and resilience was negatively associated with anxiety. As a multidimensional construct, resilience is construed as a mechanism that may foster recovery or positive growth despite the presence of symptoms of anxiety (Morote et al., 2017). Besides, resilience accounting for an essential part of the variations in anxiety symptoms may suggest that interventions should target ways to enhance resilience (Anyan \& Hjemdal, 2016). Therefore, factors of both resilience and anxiety should be considered in interventions aimed at improving mental health by promoting physical fitness. Apart from applying their mediating roles, it would also be reasonable to include other variables to explore their moderating roles and to assess which of those variables may provide a better explanation for the association between physical fitness and mental health.

Our findings have important theoretical and practical implications for understanding the development and prevention of MHPs. On a theoretical level, Blair, Cheng, and Holder (2001) have proposed a conceptual model that asserts that the components of health-related physical fitness may be the direct determinants of health outcomes (Blair et al., 2001). Our findings not only confirm the association between physical fitness and mental health but also further clarify the mechanisms underlying how physical fitness exerts this effect on levels of mental health. To the best of our knowledge, the present study is the first to elucidate the mechanisms underlying the development of children's mental health from a comprehensive physical fitness perspective. In terms of practical implications, our model suggested that physical fitness, resilience, and anxiety were associated, both directly or indirectly, with mental health in children. It could, therefore, be postulated that enhancing resilience and decreasing anxiety by increasing physical fitness may be beneficial to children's mental health. The standard test used in Chinese schools to assess physical fitness takes into account the development of children when selecting which components will be assessed. Interventions should also consider the potential associations between factors. Wang, An, Zhang, and Yang (2019) found that jazz dance exercise benefits students' physical fitness, anxiety, and mental health (Wang et al., 2019). Moreover, owing to the proliferation and ease of access to information and to the advent and emergence of the internet at the regional and world levels (Razavi, 2018), online game-based learning technology could be a cost-effective approach to improve physical activity outcomes (Belogianni et al., 2019). Recent evidence also indicates that games implemented through social networking sites appear to effectively enhance users' mental health (T. M. Li, Chau, Wong, Lai, \& Yip, 2013). As previous work has suggested, game-based learning enables children to take ownership of their learning experience and to connect with information in a way that traditional methods cannot (Partovi \& Razavi, 2019). Therefore, new forms of online interventions to promote mental health among children are necessary during pandemics. Our findings provide preliminary data that may guide programs aimed at improving mental health in children, suggesting that those activities performed during the promotion of physical fitness that targets improving resilience and decreasing anxiety may lead to even better mental health.

Some limitations should be noted when interpreting the results of our study. First, our study used a cross-sectional design, which cannot provide strong evidence for causality. It is important to highlight that drawing a conclusion of a causal link between variables through mediation analysis alone is not adequate although the results herein suggest the possibility of such a link. Therefore, longitudinal studies should be designed to validate the findings. Second, some variables were collected using self-reported questionnaires, which may affect the outcomes. Future studies should measure mental health objectively, such as through neuropsychological tests. Third, our findings were obtained from a sample population of children, and the question of whether the results are applicable to other populations will require further testing. However, the primary schools and the children selected for the present study were based on previous studies designed to assess models of physical fitness and mental indicators $(\mathrm{Gu}$, Zhang, Chu, Keller, \& Zhang, 2019; Perez-Sousa, Olivares, 
Escobar-Alvarez, Parraca, \& Gusi, 2018). Although the concept of physical fitness has changed over time around the world, its core items and components have remained similar in different countries (Dong et al., 2020). Notably, more than $90 \%$ of the comprehensive physical fitness scores for the children included in our study met the fitness testing standards, which are similar to those found in Physical Activity and Fitness in China: The Youth Study (PAFCTYS) (Zhu et al., 2017). Nevertheless, children from other countries and different cultures should be assessed in future studies.

\section{Conclusion}

The current study findings using a serial multiple mediation model provided mechanistic insights into the associations among physical fitness, resilience, anxiety, and mental health. We found that physical fitness was significantly and positively associated with children's mental health. Additionally, children with higher-level physical fitness reported greater resilience and lower-level anxiety, which in turn contributed to their mental health. Thus, physical fitness may contribute to children's mental health through the serial mediating effect of "resilience-anxiety". These findings suggest that to achieve good mental health in children, promoting physical fitness independent of considering resilience and anxiety may be insufficient. Future study is needed to confirm these findings and to reveal additional associations that may benefit the design of health interventions in children.

Acknowledgments The authors thank all the participants, volunteers, teachers, and schools for their enthusiastic participation in this study.

Data Availability The datasets generated during and/or analysed during the current study are available from the corresponding author on reasonable request.

\section{Compliance with Ethical Standards}

Conflict of Interest The authors declare no conflict of interest.

Ethical Approval The study was conducted in accordance with the recommendations of the World Medical Association's Declaration of Helsinki and approved by the Shanghai University of Sport Ethics Committee.

Informed Consent Informed consent was obtained from all individual participants included in this study.

\section{References}

Anyan, F., \& Hjemdal, O. (2016). Adolescent stress and symptoms of anxiety and depression: Resilience explains and differentiates the relationships. Journal of Affective Disorders, 203, 213-220. https://doi.org/10.1016/j.jad.2016.05.031.
Aparicio, V. A., Marin-Jimenez, N., Coll-Risco, I., de la Flor-Alemany, M., Baena-Garcia, L., Acosta-Manzano, P., \& Aranda, P. (2019). Doctor, ask your perimenopausal patient about her physical fitness; association of self-reported physical fitness with cardiometabolic and mental health in perimenopausal women: The FLAMENCO project. Menopause, 26(10), 1146-1153. https://doi.org/10.1097/ GME.0000000000001384.

Așçı, F. H. (2003). The effects of physical fitness training on trait anxiety and physical self-concept of female university students. Psychology of Sport and Exercise, 4(3), 255-264. https://doi.org/10.1016/ s1469-0292(02)00009-2.

Avitsland, A., Leibinger, E., Haugen, T., Lerum, O., Solberg, R. B., Kolle, E., \& Dyrstad, S. M. (2020). The association between physical fitness and mental health in Norwegian adolescents. BMC Public Health, 20(1), 776. https://doi.org/10.1186/s12889-02008936-7.

Barzilay, R., Moore, T. M., Greenberg, D. M., DiDomenico, G. E., Brown, L. A., White, L. K., Gur, R. C., \& Gur, R. E. (2020). Resilience, COVID-19-related stress, anxiety and depression during the pandemic in a large population enriched for healthcare providers. Translational Psychiatry, 10(1), 291. https://doi.org/10.1038/ s41398-020-00982-4.

Beecham, J. (2014). Annual research review: Child and adolescent mental health interventions: A review of progress in economic studies across different disorders. Journal of Child Psychology and Psychiatry, 55(6), 714-732. https://doi.org/10.1111/jcpp.12216.

Belcher, B. R., Zink, J., Azad, A., Campbell, C. E., Chakravartti, S. P., \& Herting, M. M. (2020). The roles of physical activity, exercise, and fitness in promoting resilience during adolescence: Effects on mental well-being and brain development. Biological Psychiatry: Cognitive Neuroscience and Neuroimaging. https://doi.org/10. 1016/j.bpsc.2020.08.005.

Belogianni, K., Ooms, A., Ahmed, H., Nikoletou, D., Grant, R., Makris, D., \& Moir, H. J. (2019). Rationale and Design of an Online Educational Program Using Game-Based Learning to improve nutrition and physical activity outcomes Among University students in the United Kingdom. Journal of the American College of Nutrition, 38(1), 23-30. https://doi.org/10.1080/07315724.2018.1476929.

Biddle, S. J. H., Ciaccioni, S., Thomas, G., \& Vergeer, I. (2019). Physical activity and mental health in children and adolescents: An updated review of reviews and an analysis of causality. Psychology of Sport and Exercise, 42, 146-155. https://doi.org/10.1016/j.psychsport. 2018.08.011.

Bittner, A., Egger, H. L., Erkanli, A., Jane Costello, E., Foley, D. L., \& Angold, A. (2007). What do childhood anxiety disorders predict? Journal of Child Psychology and Psychiatry, 48(12), 1174-1183. https://doi.org/10.1111/j.1469-7610.2007.01812.x.

Blair, S. N., Cheng, Y., \& Holder, J. S. (2001). Is physical activity or physical fitness more important in defining health benefits? Medicine \& Science in Sports \& Exercise, 33, S379-S399.

Bovet, P., Auguste, R., \& Burdette, H. (2007). Strong inverse association between physical fitness and overweight in adolescents: A large school-based survey. International Journal of Behavioral Nutrition and Physical Activity, 4, 24. https://doi.org/10.1186/ 1479-5868-4-24.

Carnahan, N. D., Carter, M. M., \& Herr, N. R. (2020). Perpetuating factors of social anxiety: A serial mediation model. Behavioural and Cognitive Psychotherapy, 48(3), 304-314. https://doi.org/10. 1017/S1352465819000638.

Chamratrithirong, A., Lucktong, A., Jampaklay, A., \& Ford, K. (2020). An analysis of the resilience process: The stimulus of mental strength and the role of community and family support amidst the civil violence in Thailand. Current Psychology. https://doi.org/10. 1007/s12144-020-01002-w.

Chronis-Tuscano, A., Molina, B. S., Pelham, W. E., Applegate, B., Dahlke, A., Overmyer, M., \& Lahey, B. B. (2010). Very early 
predictors of adolescent depression and suicide attempts in children with attention-deficit/hyperactivity disorder. Archives of General Psychiatry, 67(10), 1044-1051. https://doi.org/10.1001/ archgenpsychiatry.2010.127.

Cordoba-Torrecilla, S., Aparicio, V. A., Soriano-Maldonado, A., Estevez-Lopez, F., Segura-Jimenez, V., Alvarez-Gallardo, I., et al. (2016). Physical fitness is associated with anxiety levels in women with fibromyalgia: The al-Andalus project. Quality of Life Research, 25(4), 1053-1058. https://doi.org/10.1007/s11136-015-1128-y.

Costello, E. J., Mustillo, S., Erkanli, A., Keeler, G., \& Angold, A. (2003). Prevalence and development of psychiatric disorders in childhood and adolescence. Archives of General Psychiatry, 60(8), 837-844. https://doi.org/10.1001/archpsyc.60.8.837.

Dong, Y., Jan, C., Zou, Z., Dong, B., Hu, P., Ma, Y., Yang, Z., Wang, X., Li, Y., Gao, D., Wen, B., Song, Y., \& Ma, J. (2020). Comprehensive physical fitness and high blood pressure in children and adolescents: A national cross-sectional survey in China. Journal of Science and Medicine in Sport, 23(9), 800-806. https://doi.org/10.1016/j.jsams. 2020.02.016.

Donnelly, J. E., Hillman, C. H., Castelli, D., Etnier, J. L., Lee, S., Tomporowski, P., Lambourne, K., \& Szabo-Reed, A. N. (2016). Physical activity, fitness, cognitive function, and academic achievement in children: A systematic review. Medicine and Science in Sports and Exercise, 48(6), 1197-1222. https://doi.org/10.1249/ MSS.0000000000000901.

Gallagher, S. K., \& Mechanic, D. (1996). Living with the mentally ill: Effects on the health and functioning of other household members. Social Science \& Medicine, 42(12), 1691-1701. https://doi.org/10. 1016/0277-9536(95)00296-0.

Garcia-Hermoso, A., Esteban-Cornejo, I., Olloquequi, J., \& RamirezVelez, R. (2017). Cardiorespiratory fitness and muscular strength as mediators of the influence of fatness on academic achievement. The Journal of Pediatrics, 187, 127-133 e123. https://doi.org/10. 1016/j.jpeds.2017.04.037.

Goldfeld, S. R., \& Hayes, L. (2012). Factors influencing child mental health: A state-wide survey of Victorian children. Journal of Paediatrics and Child Health, 48(12), 1065-1070. https://doi.org/ 10.1111/j.1440-1754.2012.02473.x.

Gu, X., Zhang, T., Chu, T. L. A., Keller, M. J., \& Zhang, X. (2019). The direct and indirect effects of motor competence on adolescents' mental health through health-related physical fitness. Journal of Sports Sciences, 37(17), 1927-1933. https://doi.org/10.1080/02640414. 2019.1605652.

Guzman, M. P., Jellinek, M., George, M., Hartley, M., Squicciarini, A. M., Canenguez, K. M., Kuhlthau, K. A., Yucel, R., White, G. W., Guzman, J., \& Murphy, J. M. (2011). Mental health matters in elementary school: First-grade screening predicts fourth grade achievement test scores. European Child \& Adolescent Psychiatry, 20(8), 401-411. https://doi.org/10.1007/s00787-011-0191-3.

Hardie, J. H., \& Landale, N. S. (2013). Profiles of risk: Maternal health, socioeconomic status, and child health. Journal of Marriage and the Family, 75(3), 651-666. https://doi.org/10.1111/jomf.12021.

Hayes, A. F. (2018). Introduction to mediation, moderation, and conditional process analysis: A regression-based approach (2nd ed.). New York: The Guilford Press.

Hetrick, S. E., Parker, A. G., Hickie, I. B., Purcell, R., Yung, A. R., \& McGorry, P. D. (2008). Early identification and intervention in depressive disorders: Towards a clinical staging model. Psychotherapy and Psychosomatics, 77(5), 263-270. https://doi.org/10.1159/ 000140085

Holmes, E. A., O'Connor, R. C., Perry, V. H., Tracey, I., Wessely, S., Arseneault, L., Ballard, C., Christensen, H., Cohen Silver, R., Everall, I., Ford, T., John, A., Kabir, T., King, K., Madan, I., Michie, S., Przybylski, A. K., Shafran, R., Sweeney, A., Worthman, C. M., Yardley, L., Cowan, K., Cope, C., Hotopf, M., \& Bullmore, E. (2020). Multidisciplinary research priorities for the
COVID-19 pandemic: A call for action for mental health science. The Lancet Psychiatry, 7(6), 547-560. https://doi.org/10.1016/ s2215-0366(20)30168-1.

Hu, Y. Q., \& Gan, Y. Q. (2008). Development and psychometric validity of the resilience scale for Chinese adolescents. Acta Psychologica Sinica, 40(8), 902-912. https://doi.org/10.3724/SP.J.1041.2008. 00902.

Kandola, A., Vancampfort, D., Herring, M., Rebar, A., Hallgren, M., Firth, J., \& Stubbs, B. (2018). Moving to beat anxiety: Epidemiology and therapeutic issues with physical activity for anxiety. Current Psychiatry Reports, 20(8), 63. https://doi.org/10.1007/ s11920-018-0923-x.

Kertz, S. J., Sylvester, C., Tillman, R., \& Luby, J. L. (2019). Latent class profiles of anxiety symptom trajectories from preschool through school age. Journal of Clinical Child and Adolescent Psychology, 48(2), 316-331. https://doi.org/10.1080/15374416.2017.1295380.

Kessler, R. C., Avenevoli, S., Costello, E. J., Georgiades, K., Green, J. G., Gruber, M. J., He, J. P., Koretz, D., McLaughlin, K., Petukhova, M., Sampson, N. A., Zaslavsky, A. M., \& Merikangas, K. R. (2012). Prevalence, persistence, and sociodemographic correlates of DSMIV disorders in the National Comorbidity Survey Replication Adolescent Supplement. Archives of General Psychiatry, 69(4), 372-380. https://doi.org/10.1001/archgenpsychiatry.2011.160.

Kieling, C., Baker-Henningham, H., Belfer, M., Conti, G., Ertem, I., Omigbodun, O., Rohde, L. A., Srinath, S., Ulkuer, N., \& Rahman, A. (2011). Child and adolescent mental health worldwide: Evidence for action. Lancet, 378(9801), 1515-1525. https://doi.org/10.1016/ S0140-6736(11)60827-1.

Lavoie, J., Pereira, L. C., \& Talwar, V. (2016). Children's physical resilience outcomes: Meta-analysis of vulnerability and protective factors. Journal of Pediatric Nursing, 31(6), 701-711. https://doi.org/ 10.1016/j.pedn.2016.07.011.

Lawrence, D., Hafekost, J., Johnson, S. E., Saw, S., Buckingham, W. J., Sawyer, M. G., Ainley, J., \& Zubrick, S. R. (2016). Key findings from the second Australian child and adolescent survey of mental health and wellbeing. The Australian and New Zealand Journal of Psychiatry, 50(9), 876-886. https://doi.org/10.1177/ 0004867415617836

Li, T. M., Chau, M., Wong, P. W., Lai, E. S., \& Yip, P. S. (2013). Evaluation of a web-based social network electronic game in enhancing mental health literacy for young people. Journal of Medical Internet Research, 15(5), e80. https://doi.org/10.2196/ jmir.2316.

Liu, H., Zhang, C., Ji, Y., \& Yang, L. (2018). Biological and psychological perspectives of resilience: Is it possible to improve stress resistance? Frontiers in Human Neuroscience, 12, 326. https://doi.org/ 10.3389/fnhum.2018.00326.

Ma, D., Serbin, L. A., \& Stack, D. M. (2018). Children's anxiety symptoms and salivary immunoglobulin a: A mutual regulatory system? Developmental Psychobiology, 60(2), 202-215. https://doi.org/10. 1002/dev.21590.

Ma, D., Serbin, L. A., \& Stack, D. M. (2019). How children's anxiety symptoms impact the functioning of the hypothalamus-pituitaryadrenal axis over time: A cross-lagged panel approach using hierarchical linear modeling. Development and Psychopathology, 31(1), 309-323. https://doi.org/10.1017/S0954579417001870.

March, J. S., Parker, J. D., Sullivan, K., Stallings, P., \& Conners, C. K. (1997). The multidimensional anxiety scale for children (MASC): Factor structure, reliability, and validity. Journal of the American Academy of Child and Adolescent Psychiatry, 36(4), 554-565. https://doi.org/10.1097/00004583-199704000-00019.

Maselko, J., Sikander, S., Bangash, O., Bhalotra, S., Franz, L., Ganga, N., Rajan, D. G., O’Donnell, K., \& Rahman, A. (2016). Child mental health and maternal depression history in Pakistan. Social Psychiatry and Psychiatric Epidemiology, 51(1), 49-62. https:// doi.org/10.1007/s00127-015-1143-x. 
Morote, R., Hjemdal, O., Martinez Uribe, P., \& Corveleyn, J. (2017). Psychometric properties of the resilience scale for adults (RSA) and its relationship with life-stress, anxiety and depression in a Hispanic Latin-American community sample. PLoS One, 12(11), e0187954. https://doi.org/10.1371/journal.pone.0187954.

Ortega, F. B., Ruiz, J. R., Castillo, M. J., \& Sjostrom, M. (2008). Physical fitness in childhood and adolescence: A powerful marker of health. International Journal of Obesity, 32(1), 1-11. https://doi.org/10. 1038/sj.ijo.0803774.

Parfitt, G., Pavey, T., \& Rowlands, A. V. (2009). Children's physical activity and psychological health: The relevance of intensity. Acta Paediatrica, 98(6), 1037-1043. https://doi.org/10.1111/j.16512227.2009.01255.x.

Partovi, T., \& Razavi, M. R. (2019). The effect of game-based learning on academic achievement motivation of elementary school students. Learning and Motivation, 68. https://doi.org/10.1016/j.lmot.2019. 101592.

PeConga, E. K., Gauthier, G. M., Holloway, A., Walker, R. S. W., Rosencrans, P. L., Zoellner, L. A., \& Bedard-Gilligan, M. (2020). Resilience is spreading: Mental health within the COVID-19 pandemic. Psychological Trauma, 12(S1), S47-S48. https://doi.org/10. 1037/tra0000874.

Perez-Sousa, M. A., Olivares, P. R., Escobar-Alvarez, J. A., Parraca, J. A., \& Gusi, N. (2018). Fitness as mediator between weight status and dimensions of health-related quality of life. Health and Quality of Life Outcomes, 16(1), 155. https://doi.org/10.1186/s12955-018-0981-0.

Perou, R., Bitsko, R. H., Blumberg, S. J., Pastor, P., Ghandour, R. M., Gfroerer, J. C., et al. (2013). Mental health surveillance among children - United States, 2005-2011. Mmwr-Morbidity and Mortality Weekly Report, 62(2), 1-35.

Petrowski, K., Brahler, E., \& Zenger, M. (2014). The relationship of parental rearing behavior and resilience as well as psychological symptoms in a representative sample. Health and Quality of Life Outcomes, 12, 95.

Poudel-Tandukar, K., Chandler, G. E., Jacelon, C. S., Gautam, B., Bertone-Johnson, E. R., \& Hollon, S. D. (2019). Resilience and anxiety or depression among resettled Bhutanese adults in the United States. The International Journal of Social Psychiatry, 65(6), 496-506. https://doi.org/10.1177/0020764019862312.

Pozuelo-Carrascosa, D. P., Martinez-Vizcaino, V., Sanchez-Lopez, M., Bartolome-Gutierrez, R., Rodriguez-Martin, B., \& NotarioPacheco, B. (2017). Resilience as a mediator between cardiorespiratory fitness and mental health-related quality of life: A crosssectional study. Nursing \& Health Sciences, 19(3), 316-321. https://doi.org/10.1111/nhs.12347.

Preacher, K. J., \& Hayes, A. F. (2008). Asymptotic and resampling strategies for assessing and comparing indirect effects in multiple mediator models. Behavior Research Methods, 40(3), 879-891. https:// doi.org/10.3758/brm.40.3.879.

Razavi, M. R. (2018). Gender differences in the effect of virtual social networks use on students' academic performance. Current Psychology. https://doi.org/10.1007/s12144-018-9991-7.

Reiss, F. (2013). Socioeconomic inequalities and mental health problems in children and adolescents: A systematic review. Social Science \& Medicine, 90, 24-31. https://doi.org/10.1016/j.socscimed.2013.04.026.

Rodriguez-Ayllon, M., Cadenas-Sanchez, C., Esteban-Cornejo, I., Migueles, J. H., Mora-Gonzalez, J., Henriksson, P., Martín-
Matillas, M., Mena-Molina, A., Molina-García, P., Estévez-López, F., Enriquez, G. M., Perales, J. C., Ruiz, J. R., Catena, A., \& Ortega, F. B. (2018). Physical fitness and psychological health in overweight/obese children: A cross-sectional study from the ActiveBrains project. Journal of Science and Medicine in Sport, 21(2), 179-184. https://doi.org/10.1016/j.jsams.2017.09.019.

Schulte-Korne, G. (2016). Mental health problems in a school setting in children and adolescents. Deutsches Ärzteblatt International, 113(11), 183-190. https://doi.org/10.3238/arztebl.2016.0183.

Silverman, M. N., \& Deuster, P. A. (2014). Biological mechanisms underlying the role of physical fitness in health and resilience. Interface Focus, 4(5), 20140040. https://doi.org/10.1098/rsfs.2014. 0040.

Tang, S., Xiang, M., Cheung, T., \& Xiang, Y. T. (2020). Mental health and its correlates among children and adolescents during COVID-19 school closure: The importance of parent-child discussion. Journal of Affective Disorders, 279, 353-360. https://doi.org/10.1016/j.jad. 2020.10.016.

Waddell, C., McEwan, K., Shepherd, C. A., Offord, D. R., \& Hua, J. M. (2005). A public health strategy to improve the mental health of Canadian children. Canadian Journal of Psychiatry, 50(4), 226-233. https://doi.org/10.1177/070674370505000406.

Wang, Z., An, G., Zhang, W., \& Yang, G. (2019). The effect of jazz dance on physical and mental health of students with different physical fitness. The Journal of Sports Medicine and Physical Fitness, 59(5), 880-885. https://doi.org/10.23736/S0022-4707.18.08025-8.

Williams, S. E., Carroll, D., Veldhuijzen van Zanten, J. J., \& Ginty, A. T. (2016). Anxiety symptom interpretation: A potential mechanism explaining the cardiorespiratory fitness-anxiety relationship. Journal of Affective Disorders, 193, 151-156. https://doi.org/10. 1016/j.jad.2015.12.051.

Wyss, T., Boesch, M., Roos, L., Tschopp, C., Frei, K. M., Annen, H., \& La Marca, R. (2016). Aerobic fitness level affects cardiovascular and salivary alpha amylase responses to acute psychosocial stress. Sports Medicine Open, 2(1), 33. https://doi.org/10.1186/s40798016-0057-9.

Yi, X., Fu, Y., Burns, R. D., Bai, Y., \& Zhang, P. (2019). Body mass index and physical fitness among Chinese adolescents from Shandong Province: A cross-sectional study. BMC Public Health, 19(1), 81. https://doi.org/10.1186/s12889-019-6420-2.

Zhao, F., \& Yu, G. (2016). Parental migration and rural left-behind Children's mental health in China: A meta-analysis based on mental health test. Journal of Child and Family Studies, 25(12), 3462-3472. https://doi.org/10.1007/s10826-016-0517-3.

Zhu, Z., Yang, Y., Kong, Z., Zhang, Y., \& Zhuang, J. (2017). Prevalence of physical fitness in Chinese school-aged children: Findings from the 2016 physical activity and fitness in China-the youth study. Journal of Sport and Health Science, 6(4), 395-403. https://doi. org/10.1016/j.jshs.2017.09.003.

Zurita-Ortega, F., Chacon-Cuberos, R., Cofre-Bolados, C., Knox, E., \& Muros, J. J. (2018). Relationship of resilience, anxiety and injuries in footballers: Structural equations analysis. PLoS One, 13(11), e0207860. https://doi.org/10.1371/journal.pone.0207860.

Publisher's Note Springer Nature remains neutral with regard to jurisdictional claims in published maps and institutional affiliations. 